\title{
PENGARUH MASASE KAKI TERHADAP PENURUNAN TEKANAN DARAH PADA KELOMPOK DEWASA YANG MENGALAMI HIPERTENSI
}

\author{
Armen Patria, Richta Puspita Haryani \\ Universitas Mitra Indonesia, Bandar Lampung \\ E-mail: armenpatria@umitra.ac.id
}

\begin{abstract}
ABSTRAK
Hipertensi adalah suatu keadaan dimana terjadi peningkatan tekanan darah lebih dari $140 / 90 \mathrm{mmHg}$ dan terus menerus pada beberapa kali pemeriksaan tekanan darah yang disebabkan oleh satu atau beberapa faktor resiko yang tidak berjalan sebagaimana mestinya dalam mempertahankan tekanan darah secara normal. Faktor risiko hipertensi antara lain adalah: faktor genetik, umur, jenis kelamin, etnis, stress, obesitas/kegemukan, asupan garam, asupan kolesterol tinggi, kopi dan kebisaaan merokok selain usia dan faktor genetik. Tidak dapat dipungkiri bahwa hingga saat ini,obat tradisional dan terapi komplementer masih menjadi pilihan masyarakat dalam mengobati diri sendiri. Salah satu terapi komplementer yang dilakukan yaitu Masase kaki. Tujuan penelitian ini adalah untuk mengetahui pengaruh masase kaki terhadap penurunan tekanan darah pada kelompok dewasa yang mengalami hipertensi di wilayah kerja puskesmas Gisting Kabupaten Tangamus. Metodologi dalam penelitian ini menggunakan desain Quasy eksperimen dengan rancangan one group Pre Post Test yaitu rancangan yang dilaksanakan pada satu kelompok. Populasi dalam penelitian ini adalah penderita hipertensi derajat 1 yang berobat pada bulan Mei di Puskesmas Gisting dan berdomisili di wilayah kerja Puskesmas Gisting. Adapun jumlah populasi yaitu 30 orang pasien hipertensi derajat 1 . Hasil penelitian dapatkan P Value Hasil uji statistic didapatkan $\mathrm{p}$ Value 0.000 untuk tekanan sistolik dan p Value 0.001 untuk tekanan diastolik, yang berarti pada nilai $\alpha$ 0.05 dapat disimpulkan terdapat pengaruh masase kaki terhadap penurunan tekanan darah pada kelompok dewasa yang mengalami hipertensi di wilayah kerja puskesmas Gisting. Disarankan untuk peneliti selanjutnya melakukan penelitian dengan membandingkan terapi masase kaki dengan terapi alternative lain agar didapatkan hasil terapi yang lebih signifikan dapat menurunkan tekanan darah.
\end{abstract}

Kata Kunci : Hipertensi, Masase Kaki, Tekanan Darah

\begin{abstract}
Hypertension is a condition in which an increase in blood pressure is more than $140 / 90 \mathrm{mmHg}$ and is continuous at several blood pressure checks due to one or more risk factors that are not working properly in maintaining normal blood pressure. Hypertension risk factors include: genetic factors, age, gender, ethnicity, stress, obesity / obesity, salt intake, high cholesterol intake, coffee and smoking as well as age and genetic factors. It can not be denied that until now, traditional medicine and complementary therapy are still the people's choice in self-medication. One of the complementary therapies that is done is foot massage. The purpose of this study is to know Influence of Foot Massage Against Blood Pressure Reduction In Adults Who Have Hypertension at Working Area of Puskesmas Gisting 2018. Metodology in this study used a Quasy experimental design with one group Pre Post Test design is implemented in one group. Population in this research is patient of degree 1 hypertension that treatment in May at Puskesmas Gisting and domiciled in working area of Gisting Health Center. The number of population is 30 people with hypertension degree 1. The results obtained P Value Statistical test results obtained $p$ Value 0.000 for systolic pressure and $p$ Value 0.001 for diastolic pressure, which means at the value of a 0.05 can be concluded there is influence foot massage to decrease blood pressure in the adult group who experienced hypertension in the work area of Gisting puskesmas. It is recommended for further research to do research by comparing foot massage therapy with other alternative therapy in order to get a more significant therapy results can lower blood pressure.
\end{abstract}

Keyword : Hypertension, Foot Massage, Blood Pressure 


\section{PENDAHULUAN}

Hipertensi adalah suatu keadaan dimana terjadi peningkatan tekanan darah lebih dari 140/90 $\mathrm{mmHg}$ dan terus menerus pada beberapa kali pemeriksaan tekanan darah yang disebabkan oleh satu atau beberapa factor resiko yang tidak berjalan sebagaimana mestinya dalam mempertahankan tekanan darah secara normal (Wijya \& Putri, 2013).

WHO mencatat bahwa dua per tiga dari penduduk dunia yang menderita hipertensi diantaranya berada di Negara berkembang yang berpenghasilan rendah dan sedang seperti negara-negara di benua asia. Prevalensi kejadian hipertensi tertinggi di asia adalah negara Myanmar yaitu sebesar $37.7 \%$, India $36.5 \%$, Srilanka 34.7\%, dan Thailand 33.3\% (WHO 2015, Dalam Infodatin 2016)

Sedangkan prevalensi hipertensi di Indonesia yang didapat melalui pengukuran tekanan darah pada umur $\geq 18$ tahun sebesar 25,8 \%, tertinggi di Bangka Belitung (30,9\%), diikuti Kalimantan Selatan (30,8\%), Kalimantan Timur (29,6\%) dan Jawa Barat $(29,4 \%)$ (Riskesdas, 2013).

Berdasarkan data Dinas Kesehatan Provinsi Lampung Tahun 2016, jumlah yang terdata hipertensi 30,17\% dengan jumlah laki-laki $29,05 \%$ dan perempuan 19,35\%,di bandingkan dengan Tahun 2015 lebih tinggi angka hipertensi dengan persentase 53,77\% dengan jumlah laki-laki $76,92 \%$ dan perempuan 44,34\%. Sedangkan menurut Data Dinas Kesehatan Kabupaten Tanggamus, hipertensi termasuk dalam 5 besar penyakit terbanyak. Pada tahun 2015, penderita hipertensi sebanyak 5.755 orang dan mengalami peningkatan pada tahun 2016 dengan jumlah penderita sebanyak 13.512 orang (Provil Dinas Kesehatan Provinsi Lampung, 2017).

Sedangkan dari hasil pra-survey yang peneliti lakukan diketahui bahwa terjadi peningkatan kasus hipertensi. Pada tahun 2016 hipertensi menepati urutan ke 6 penyakit yang diderita sedangkan pada tahun 2017 mengalami peningkatan menjadi penyakit terbanyak ke 4 yang dialami di puskesmas gisting. Dari hasil wawancara yang peneliti lakukan di tempat penelitian diketahui bahwa perawat atau petugas kesehatan di tempat penelitian tidak memberikan edukasi terkait dengan terapi alternative lain yang dapat membantu menurunkan tekanan darah pada pasien hipertensi di tempat penelitian

Penyakit hipertensi merupakan salah satu faktor resiko utama terjadinya gangguan jantung. Selain mengakibatkan gagal jantung, hipertensi dapat berakibat terjadinya gagal ginjal maupun penyakit serebrovaskular. Pada kebanyakan kasus, hipertensi terdeteksi saat pemeriksaan fisik karena alasan penyakit tertentu, sehingga sering disebut sebagai "silent killer". Banyak faktor yang dapat 
menyebabkan terjadinya hipertensi. Faktor risiko hipertensi antara lain adalah: faktor genetik, umur, jenis kelamin, etnis, stress, obesitas/ kegemukan, asupan garam, asupan kolesterol tinggi, kopi dan kebisaaan merokok selain usia dan faktor genetik (Wijaya \& Putri 2013).

Di beberapa negara, obat tradisional dan terapi komplementer telah dimanfaatkan dalam pelayanan kesehatan formal terutama dalam pelayanan kesehatan strata pertama. Tidak dapat dipungkiri bahwa hingga saat ini,obat tradisional dan terapi komplementer masih menjadi pilihan masyarakat dalam mengobati diri sendiri, namun rendahnya pengetahuan tentang terapi komplementer untuk mengatasi hipertensi sehingga masyarakat di tempat penelitian tidak mengerti dan tidak mencoba terapi lain selain obat-obatan, untuk itu peneliti tertarik melakukan sebuah penelitian yang bertujuan member terapi komplementer dengan judul pengaruh masase kaki terhadap penurunan tekanan darah (Padila, 2012).

Masase atau pijat adalah penggunaan tekanan dan gerakan yang bervariasi untuk memanipulasi otot dan jaringan lunak lainnya. Dengan melemaskan jaringan lunak tubuh, lebih banyak darah dan oksigen dapat mencapai daerah yang terkena dampak dan mengurangi nyeri. Masase merupakan teknik integrasi sensori yang mempengaruhi aktivitas sistem saraf otonom. Apabila seseorang mempersepsikan sentuhan sebagai stimulus rileks maka akan muncul respon relaksasi (Dalimartha, 2012).

Hasil penelitian yang dilakukan oleh Fitriani (2015) dengan judul Pengaruh masase kaki terhadap penurunan tekanan darah pada penderita hipertensi di wilayah kerja puskesmas Bontomarannu Kabupaten Gowa didapatkan hasil didapatkan bahwa semua responden merupakan hipertensi primer yaitu sebanyak 20 responden (100\%) dan terdapa hubungan antara masase kaki dengan penurunan tekanan darah pada penderita hipertensi dimana hasil uji $p 0.004$ (tekanan darah sistol) dan $p=0.005$ (tekanan darah diastol) yang artinya ada hubungan yang signifikan. Selain itu, diperoleh bahwa masase kaki yang baik sebanyak 20 responden (100\%) mengatakan puas dan tidak ada yang mengatakan tidak puas selama diberikan intervensi masase kaki.

Tingginya angka kejadian hipertensi dan juga terjadinya peningkatan angka kejadian hipertensi serta minimnya edukasi yang dimiliki oleh masyarakat tentang terapi komplementer yang dapat membantu menurunkan tekanan darah maka peneliti tertarik untuk melakukan sebuah penelitian yang berjudul "pengaruh masase kaki terhadap penurunan tekanan darah pada kelompok dewasa yang mengalami hipertensi 
di wilayah kerja puskesmas Gisting Tahun $2018 ”$

\section{METODOLOGI}

Penelitian ini menggunakan desain Quasy eksperimen dengan rancangan one group Pre Post Test yaitu rancangan yang dilaksanakan pada satu kelompok (Hidayat 2011).

Populasi dalam penelitian ini adalah penderita hipertensi derajat 1 yang berobat pada bulan Mei di Puskesmas Gisting dan berdomisili di wilayah kerja Puskesmas Gisting. Adapun jumlah populasi yaitu 30 orang pasien hipertensi derajat 1. Sampel dalam penelitian ini sebanyak 30 responden.

Dalam penelitian ini peneliti melakukan pengambilan sampel melalui tehnik Accidental Sampling yaitu dengan menunggu pasien yang berobat atau muncul pada saat penelitian berlangsung (Hidayat, 2011).

Analisa data digunakan untuk mengolah data yang diperoleh dengan menggunakan program software computer dimana akan dilakukan 2 macam analisa data, yaitu analisa univariat dan analisa bivariat.

Analisa ini digunakan untuk menggambarkan rata-rata tekanan darah sebelum diberikan intervensi dan rata-rata tekanan darah setelah diberikan intervensi.

Uji statistik yang digunakan dalam penelitian ini adalah uji $T$ (Dependent samples T-Test). Pada penelitian ini menggunakan nilai $\alpha$ sebesar 0.05 yang memiliki tingkat kemaknaan $95 \%$.

\section{HASIL}

Tabel 1.

Distribusi umur Responden yang mengalami hipertensi di wilayah kerja Puskesmas Gisting tahun 2018

\begin{tabular}{ccc}
\hline Umur & Frekuensi & Persentase \\
\hline 18-30 Tahun & 5 & 16.7 \\
31- 50 Tahun & 12 & 40.0 \\
>50 Tahun & 13 & 43.4 \\
& & \\
\hline Total & 30 & 100.0 \\
\hline
\end{tabular}

Berdasarkan tabel 1. diketahui bahwa lebih banyak responden yang berusia antara 31-50 tahun yaitu sebanyak 12 (40.0\%).

Tabel 2.

Distribusi Jenis KelaminResponden yang mengalami hipertensi di wilayah kerja puskesmas Gisting Tahun 2018

\begin{tabular}{lcc}
\hline \multicolumn{1}{c}{ Jenis Kelamin } & Frekuensi & Persentase \\
\hline Laki-laki & 16 & 53.3 \\
Perempuan & 14 & 46.7 \\
\hline \multicolumn{1}{c}{ Total } & 30 & 100.0 \\
\hline
\end{tabular}

Berdasarkan tabel 2. diketahui bahwa lebih banyak responden yang berjenis kelamin lakilaki yaitu sebanyak $16(53.3 \%)$

Tabel 3

Distribusi Pendidikan Responden yang mengalami hipertensi di wilayah kerja puskesmas Gisting Tahun 2018Jenis Kelamin

\begin{tabular}{lcc}
\hline & Frekuensi & Persentase \\
\hline SD-SMP & 13 & 43.3 \\
SLTA & 13 & 43.3 \\
Perguruan & 4 & 13.3 \\
Tinggi & & \\
\hline \multicolumn{1}{c}{ Total } & 30 & 100.0 \\
\hline
\end{tabular}


Berdasarkan tabel 3. diketahui bahwa responden yang memiliki pendidikan SD-SLTP DAN SLTA jumlahnya sama yaitu $13(43.3 \%)$.

\section{Analisa Univariat}

Tabel 4.

Tekanan darah pada responden sebelum diberikan terapi masase kaki pada kelompok dewasa yang mengalami hipertensi di wilayah kerja puskesmas Gisting Tahun 2018

\begin{tabular}{lcccc}
\hline & Mean & SD & $\begin{array}{c}\text { Minimum } \\
\text { Maximum }\end{array}$ & $\begin{array}{c}\text { 95\% } \\
\text { CI }\end{array}$ \\
\hline Sistolik & 146.17 & 5.6 & 140 & 144.05 \\
Sebelum & & & 155 & 148.29 \\
& & & & \\
Diastolik & 87.33 & 7.7 & 70 & 84.44 \\
Sebelum & & & 100 & 90.22 \\
& & & & \\
\hline
\end{tabular}

Berdasarkan tabel 4. diketahui bahwa rata-rata tekanan darah sistolik responden sebelum diberikan intervensi yaitu $146.17 \quad$ (95\% \% CI : 144.05148.29), tekanan darah terendah 140 dan tekanan darah tertinggi 155 . Sedangkan diketahui tekanan darah diastolik sebelum diberikan intervensi yaitu 87.33 (95\%\% CI : 84.44-90.22), tekanan darah terendah adalah 70 dan tertinggi adalah 100 .

\section{Tabel 5.}

Tekanan darah pada responden sesudah diberikan terapi masase kaki pada kelompok dewasa yang mengalami hipertensi di wilayah kerja puskesmas Gisting Tahun 2018

\begin{tabular}{lcccc}
\hline & Mean & SD & $\begin{array}{c}\text { Minimum } \\
\text { Maximum }\end{array}$ & $\begin{array}{c}\mathbf{9 5 \%} \\
\text { CI }\end{array}$ \\
\hline Sistolik & 136.33 & 8.8 & 120 & 133.01 \\
Sesudah & & & 150 & 139.66 \\
& & & & \\
& 83.00 & 7.4 & 70 & 80.20 \\
Diastolik & & & 90 & 85.80 \\
Sesudah & & & & \\
& & & &
\end{tabular}

Berdasarkan tabel 5. diketahui bahwa rata-rata tekanan darah sistolik responden sesudah diberikan intervensi yaitu $136.33 \quad(95 \%$ \% CI : 133.01139.66), tekanan darah terendah 120 dan tekanan darah tertinggi 150 Sedangkan rata-rata tekanan darah diastolic responden setelah diberikan intervensi yaitu $83.00 \quad(95 \%$ \% CI : 80.20-85.80), tekanan darah diastolic terendah adalah 70 dan tertinggi 90 . 


\section{Analisa Bivariat}

Tabel 6.

Pengaruh masase kaki terhadap penurunan tekanan darah pada kelompok dewasa yang mengalami hipertensi di wilayah kerja puskesmas Gisting Tahun 2018

\begin{tabular}{|c|c|c|c|c|c|}
\hline & Mean & SD & SE & $\begin{array}{c}\mathbf{P} \\
\text { Value }\end{array}$ & $\mathbf{N}$ \\
\hline $\begin{array}{l}\text { Tekanan } \\
\text { darah } \\
\text { sistolik } \\
\text { sebelum } \\
\text { diberikan } \\
\text { intervensi }\end{array}$ & 146.17 & 5.6 & 1.0 & 0.000 & 30 \\
\hline $\begin{array}{l}\text { Tekanan } \\
\text { darah } \\
\text { sistolik } \\
\text { sesudah } \\
\text { diberikan } \\
\text { intervensi }\end{array}$ & 136.33 & 8.8 & 1.6 & & \\
\hline $\begin{array}{l}\text { Tekanan } \\
\text { darah } \\
\text { diastolik } \\
\text { sebelum } \\
\text { diberikan } \\
\text { intervensi }\end{array}$ & 87.33 & 7.7 & 1.1 & 0.001 & 30 \\
\hline $\begin{array}{l}\text { Tekanan } \\
\text { darah } \\
\text { diastolik } \\
\text { sesudah } \\
\text { diberikan } \\
\text { intervensi }\end{array}$ & 83.00 & 7.4 & 1.3 & & \\
\hline
\end{tabular}

Berdasarkan tabel 6. diketahui bahwa terdapat perbedaan rata-rata tekanan darah sistolik dan diastolik sebelum dan sesudah diberikan intervensi, sebelum diberikan intervensi rata-rata tekanan darah sistolik responden adalah 146.17 dan diastolik 87.33, sedangkan rata-rata tekanan darah pada responden setelah diberikan intervensi yaitu tekanan rata-rata tekanan darah sistolik 136.33 dan diastolik 83.00. Pada hasil analisis didapatkan p Value 0.000 untuk tekanan sistolik dan $\mathrm{p}$ Value 0.001 untuk tekanan diastolik, yang berarti pada nilai $\alpha 0.05$ dapat disimpulkan terdapat pengaruh masase kaki terhadap penurunan tekanan darah pada kelompok dewasa yang mengalami hipertensi di wilayah kerja puskesmas Gisting Tahun 2018.

Terdapat perubahan rata-rata tekanan darah setelah diberikan intervensi berupa masase kaki yaitu rata-rata tekanan darah sistolik responden sesudah diberikan intervensi yaitu 136.33, tekanan darah terendah 120 dan tekanan darah tertinggi 150. Sedangkan rata-rata tekanan darah diastolic responden setelah diberikan intervensi yaitu 83.00, dan tekanan darah diastolik terendah adalah 70 dan tertinggi 90 . Data tersebut menunjukan bahwa terdapat penurunan rata-rata tekanan darah. Berdasarkan hasil penelitian diketahui bahwa sebelum diberikan intervensi rata-rata tekanan darah responden yaitu sistolik 146.17, tekanan darah terendah 140 dan tekanan darah Tertinggi 155. 
Tekanan darah diastolik sebelum diberikan intervensi yaitu 87.33 dan tekanan darah diastolik terendah adalah 70 dan tertinggi adalah 100. yang signifikan sebelum dan sesudah diberikan masase kaki.

\section{PEMBAHASAN}

Hasil penelitian menunjukan bahwa terdapat perbedaan rata-rata tekanan darah sistolik dan diastolik sebelum dan sesudah diberikan intervensi, sebelum diberikan intervensi ratarata tekanan darah sistolik responden adalah 146.17 dan diastolik 87.33, sedangkan ratarata tekanan darah pada responden setelah diberikan intervensi yaitu tekanan rata-rata tekanan darah sistolik 136.33 dan diastolik 83.00. Pada hasil analisis didapatkan $\mathrm{p}$ Value 0.000 untuk tekanan sistolik dan p Value 0.001 untuk tekanan diastolik, yang berarti pada nilai $\alpha 0.05$ dapat disimpulkan terdapat pengaruh masase kaki terhadap penurunan tekanan darah pada kelompok dewasa yang mengalami hipertensi di wilayah kerja puskesmas Gisting Tahun 2018.

Menurut Wijaya \& Putri (2013), prinsip pijat pada penderita hipertensi adalah untuk memperlancar aliran energi dalam tubuh sehingga gangguan peningkatan tekanan darah dapat dihindari dan dapat menurunkan darah pada penderita hipertensi. Ketika semua jalur energi terbuka dan tidak ada penghalang oleh ketegangan otot maka dapat memperlancar aliran darah dan menurunkan tekanan darah pada pasien hipertensi.

Pijat kaki menimbulkan relaksasi yang dalam sehingga meringankan kelelahan jasmani dan rohani dikarenakan sistem saraf simpatis mengalami penurunan aktivitas yang akhirnya mengakibatkan turunnya tekanan darah. pada prinsipnya pijat yang dilakukan pada penderita hipertensi adalah untuk memperlancar aliran energy dalam tubuh sehingga gangguan hipertensi dan komplikasinya dapat diminimalisir, ketika semua jalur energi terbuka dan aliran energi tidak lagi terhalang oleh ketegangan otot dan hambatan lain maka risiko hipertensi dapat ditekan. Penatalaksanaan yang telah dikemukakan diatas bertujuan untuk menurunkan tekanan darah dengan mengurangi jumlah darah, mengurangi kegiatan jantung memompa, dan mengurangi mengerutnya dinding-dinding pembuluh nadi halus sehingga tekanan pada dinding-dinding pembuluh darah berkurang dan aliran darah menjadi lancar sehingga tekanan darah akan menurun (Dalimartha, 2012).

Pijat kaki yang dilakukan dengan cara memijat bagian di kaki, dapat memberikan rangsangan relaksasi yang mampu memperlancar aliran darah dan cairan tubuh pada bagian-bagian tubuh yang berhubungan dengan titik syaraf kaki yang dipijat sehingga 
dapat menurunkan tekanan darah (Dalimartha, 2012).

Hasil yang sama juga didapatkan oleh penelitian yang dilakukan oleh Herliawati dan Ramadhani (2010) dengan judul pengaruh masase kaki dengan minyak esensial lavender terhadap penurunan tekanan darah penderita hipertensi primer usia 45-59 tahun di kelurahan timbangan Kecamatan Indralaya Utara Kabupaten Ogan Ilir. Berdasarkan hasil penelitian terdapat perbedaan penurunan tekanan darah yang signifikan antara sebelum dan sesudah masase kaki dengan minyak esensial lavender (sistolik: $\mathrm{t}=35,699 \mathrm{p}=0,000$; diastolik: $\mathrm{t}=14,882, \mathrm{p}=0,000)$.

Hasil penelitian yang sama juga di dapaatkan oleh Ananto (2017) dengan judul pengaruh massage teknik effleurage terhadap tekanan darah pada penderita hipertensi di desa Kalirejo Kabupaten Purworejo. Hasil penelitian diperoleh bahwa pemberian massage teknik effleurage pada bagian punggung, dan ekstremitas atas pada penderita hipertensi di Desa Kalirejo Kabupaten Purworejo dapat menurunkan tekanan darah sistolik dari 156,60 $\mathrm{mmHg}$ menjadi 141,33 $\mathrm{mmHg}$, dan tekanan darah diastolik dari $87,60 \mathrm{mmHg}$ menjadi 81,20 $\mathrm{mmHg}$ dengan nilai $\mathrm{p}$ value $=0.000(\mathrm{p}<$ $0,05)$.
Pijat pada kaki dapat menyebabkan terjadinya rileks pada responden dan juga dapat mengurangi stress, dimana salah satu faktor yang meningkatkan tekanan darah adalah stress. Selain itu dengan memberikan pijatan maka aliran darah vena menuju jantung akan lebih baik sehingga dapat menurunkan tekanan darah. Berdasarkan hasil penelitian, teori terkait dan hasil penelitian terdahulu maka peneliti menyimpulkan bahwa terdapat pengaruh masase kaki terhadap penurunan tekanan darah pada kelompok dewasa yang mengalami hipertensi di wilayah kerja puskesmas Gisting Tahun 2018.

\section{KESIMPULAN}

Berdasarkan hasil penelitian yang telah peneliti lakukan di puskesmas Gisting maka didapatkan kesimpulan sebagai hasil dari penelitian sebagai berikut :

a. Diketahui tekanan darah pada responden sebelum diberikan terapi masase kaki pada kelompok dewasa yang mengalami hipertensi rata-rata tekanan darah sistolik 146.17 diastolik $87.33 \mathrm{mmHg}$

b. Diketahui tekanan darah pada responden setelah diberikan terapi masase kaki pada kelompok dewasa yang mengalami ratarata tekanan darah sistolik 136.33 diastolik 80.

c. Ada pengaruh masase kaki terhadap penurunan tekanan darah pada kelompok dewasa yang mengalami hipertensi di 
wilayah kerja puskesmas Gisting Tahun 2018 dengan $\mathrm{p}$ Value 0.000 untuk sistolik dan $\mathrm{p}$ Value 0.001 untuk diastolik.

\section{KEPUSTAKAAN}

Ananto, D. P. (2017). Pengaruh Massage Teknik Effleurage terhadap Tekanan Darah pada Penderita Hipertensi di Desa Kalirejo Kabupaten Purworejo Dalimartha, 2012. Care Your Self; Hipertensi. Jakarta: Penebar Plus

Fitriani, F. (2015). Pengaruh Masase Kaki Terhadap Penurunan Tekanan Darah pada Penderita Hipertensi di Wilayah Kerja Puskesmas Bontomarannu Kabupaten Gowa (Doctoral dissertation, Universitas Islam Negeri Alauddin Makassar).

Herliawati, h., \& Ramadhani, R. (2010) Pengaruh masase kaki dengan minyak esensial lavender terhadap penurunan tekanan darah penderita hipertensi primer usia 45-59 tahun di kelurahan timbangan kecamatan indralaya utara kabupaten ogan ilir. Eprints unsri.

Hidayat, Azizi Alimul. 2011. Metode penelitian keperawatan dan analisis data. Jakarta Salemba Medika.

Infodatin. 2016. Pusat informasi dan data kementrian kesehatan Hipertensi. Jakarta : Kementrian Kesehatan RI

Padila. 2012. Buku ajar : Keperawatan Medikal Bedah. Bengkulu : Salemba Medika

Profil Dinas Kesehatan Provinsi Lampung. 2017

Riskesdas. 2013. Riset Kesehatan Dasar Badan Penelitian Dan Pengembangan Kesehatan. Jakarta : Kementrian Kesehatan RI.

Wijaya \& Putri. 2013. Keperawatan medikal bedah pada dewasa. Bengkulu : Nuhamedika 